\title{
Prostacyclin Biosynthesis in
}

\section{Cultured Vascular Endothelium is Limited by Deactivation of Cyclooxygenase}

\author{
Abigail F. Adams Brotherton and John C. Hoak, Cardiovascular Center and \\ Division of Hematology-Oncology, Department of Medicine, \\ University of Iowa, Iowa City, Iowa 52242
}

\begin{abstract}
A B S T R A C T Primary monolayer cultures of human umbilical vein endothelium produce prostacyclin $\left(\mathrm{PGI}_{2}\right)$ in response to stimulation by thrombin, ionophore A23187, arachidonic acid, and the prostaglandin endoperoxide, $\mathrm{PGH}_{2}$. None of these treatments had a significant effect on the capacity of the endothelium to produce $\mathrm{PGI}_{2}$ in response to subsequent stimulation by $\mathrm{PGH}_{2}$. By contrast, endothelium initially exposed to thrombin, A23187, or arachidonic acid produced $\sim 37,68$, and $84 \%$ less $\mathrm{PGI}_{2}$, respectively, upon subsequent stimulation by arachidonic acid. These findings suggest that $\mathrm{PGI}_{2}$ biosynthesis in cultured endothelium results in deactivation of cyclooxygenase-hydroperoxidase but not $\mathrm{PGI}_{2}$ synthetase. To test the hypothesis that $\mathrm{PGI}_{2}$ biosynthesis alone causes deactivation of cyclooxygenase, thrombin, A23187, and arachidonic acid were added to monolayers that had been preincubated with ibuprofen $(250$ $\mu \mathrm{M})$, a rapidly reversible, competitive inhibitor of this enzyme. After removal of the ibuprofen and the initial stimulus, $\mathrm{PGI}_{2}$ production in response to subsequent stimulation by arachidonic acid was maximal. These findings suggest that the metabolism of arachidonic acid itself causes a direct deactivation of cyclooxygenase. After an initial exposure to arachidonic acid, $\mathrm{PGI}_{2}$ production in response to a second stimulation by arachidonic acid was restored to $\sim 34,69$, and $74 \%$ of maximal, after recovery periods of 1,24 , and $48 \mathrm{~h}$,
\end{abstract}

This material was presented, in part, before the Midwest Section of the American Federation for Clinical Research, 4-6 November 1982, and the American Heart Association, 15-18 November 1982.

Address reprint requests to Dr. Brotherton.

Received for publication 7 March 1983 and in revised form 26 May 1983. respectively. We conclude that the regulation of $\mathrm{PGI}_{2}$ biosynthesis in normal vascular endothelium may be in part a function of the activity and biosynthesis of cyclooxygenase-hydroperoxidase and that deactivation of this enzyme may be a primary factor limiting the capacity of the endothelium to produce $\mathrm{PGI}_{2}$.

\section{INTRODUCTION}

Prostacyclin $\left(\mathrm{PGI}_{2}\right)^{1}$ is a potent vasodilator, inhibitor of platelet aggregation (1), and agonist of adenylate cyclase (2), which is produced by vascular endothelium in response to a variety of stimuli $(3,4)$. At present, very little is known regarding the mechanisms involved in the regulation of $\mathrm{PGI}_{2}$ biosynthesis in endothelium. Several years ago, both we (5) and Weksler et al. (3) observed that the capacity of endothelial cells grown in culture to produce $\mathrm{PGI}_{2}$ was not unlimited. Both primary (5) and passed (3) monolayer cultures of human umbilical vein endothelium that produced $\mathrm{PGI}_{2}$ upon stimulation with thrombin failed to respond to a second exposure to thrombin. Weksler et al. (3) also reported that monolayers stimulated first with arachidonic acid responded poorly to a subsequent stimulation by thrombin. These findings suggested several explanations, the two most likely being a productmediated negative feedback mechanism or deactivation of one or more of the enzymes of $\mathrm{PGI}_{2}$ biosynthesis. Although self-regulation of prostaglandin (PG) production by a cyclic AMP-mediated negative feed-

\footnotetext{
${ }^{1}$ Abbreviations used in this paper: $\mathrm{H} / \mathrm{H}$ buffer, Hanks' balanced salt solution without $\mathrm{NaHCO}_{3} ; \mathrm{PG}$, prostaglan$\operatorname{din}(s)$, with the corresponding letter $(F, H)$ for each series; $\mathrm{PGI}_{2}$, prostacyclin.
} 
back mechanism is an attractive hypothesis, we have conclusively demonstrated that such a mechanism is not involved in the short-term regulation of $\mathrm{PGI}_{2}$ biosynthesis in primary cultures of human umbilical vein endothelium (6). On the other hand, Egan et al. $(7,8)$ have shown that microsomal as well as purified preparations of prostaglandin cyclooxygenase-hydroperoxidase (endoperoxide synthetase) become irreversibly deactivated during catalysis. Deactivation has been attributed to attack on the enzyme by an oxidizing species formed in situ by the hydroperoxidase (7). This oxidizing species has also been reported to deactivate $\mathrm{PGI}_{2}$ synthetase (9). In light of these findings, this study was designed to determine whether deactivation of cyclooxygenase and/or $\mathrm{PGI}_{2}$ synthetase occurs in endothelium grown in culture and whether it plays a role in the regulation of $\mathrm{PGI}_{2}$ biosynthesis. Evidence presented in this paper suggests that cyclooxygenase, but not $\mathbf{P G I}_{2}$ synthetase, becomes deactivated during $\mathbf{P G I}_{2}$ biosynthesis. Preliminary results have been reported in abstract form (10).

\section{METHODS}

Reagents. $\mathrm{PGH}_{2}$ was biosynthesized according to the method of Gorman et al. (11). Arachidonic acid was purchased from Nu-Chek Prep., Inc. (Elysian, MN) and A23187 from Calbiochem-Behring Corp., American Hoechst Corp. (San Diego, CA). Stock solutions $(10 \mathrm{mM})$ of both arachidonic acid and A23187 were prepared using dimethyl sulfoxide as the diluent; $20-\mu$ l aliquots of these solutions were kept at $-80^{\circ} \mathrm{C}$ until use. $\mathrm{Na}$ ibuprofen (Motrin) was a gift from the Upjohn Co. (Kalamazoo, MI). L-Ascorbic acid, $n$-propyl gallate, dithiothreitol, and glutathione (reduced form) were purchased from Sigma Chemical Co. (St. Louis, MO); phenyl-methyl-sulfide (thioanisole) was from Aldrich Chemical Co. (Milwaukee, WI). The sources of other agents used are described elsewhere $(4,5,12,13)$.

Cell culture. Primary cultures of human endothelial cells from umbilical veins were prepared by a modification (13) of the method of Jaffe et al. (14). Confluent endothelial cell monolayers containing $\sim 4.5 \times 10^{5}$ cells $/ 24-\mathrm{mm}$ diam well of a 12-well plate (Linbro Chemical Co., Hamden, CT) were used 3-4 $\mathrm{d}$ after seeding.

Incubation procedure. Immediately before each experiment, culture medium was aspirated and monolayers were rinsed twice with $1 \mathrm{ml}$ of " $\mathrm{H} / \mathrm{H}$ buffer" (Hanks' balanced salt solution (without $\mathrm{NaHCO}_{3}$ ) (Gibco Laboratories, Grand Island, NY); buffered to $\mathrm{pH} 7.4$ with $15 \mathrm{mM}$ Hepes. Unless indicated otherwise, monolayers were incubated for $10 \mathrm{~min}$ at $37^{\circ} \mathrm{C}$ with $500 \mu \mathrm{l}$ of $\mathrm{H} / \mathrm{H}$ buffer alone ( \pm vehicle; $0.04 \%$ dimethyl sulfoxide) or containing a test stimulus. At the end of the incubation period, the incubation medium was removed from the monolayers. When a second incubation was carried out, monolayers were immediately rinsed twice with $1 \mathrm{ml}$ of $\mathrm{H} / \mathrm{H}$ buffer before the addition of buffer or stimulus. Incubation medium removed from the monolayers was frozen at $-20^{\circ} \mathrm{C}$ until it was assayed for 6-keto-PGF ${ }_{1 \alpha}$. In these studies, monolayers were not rocked during incubation periods as we have found that the amount of $\mathrm{PGI}_{2}$ produced in response to any stimulus tested is unaffected by agitation (data not shown).
Radioimmunoassay of 6-keto-PGF $1 \alpha$. The radioimmunoassay of 6-keto-PGF is $_{1 \alpha}$ is described elsewhere (5). Assay detection limits are $0.25 \mathrm{pmol}$ of 6 -keto- $\mathrm{PGF}_{1 \alpha} / \mathrm{ml}$, and $50 \%$ displacement of $\left[{ }^{3} \mathrm{H}\right] 6$-keto-PGF ${ }_{1 \alpha}$ is obtained with 1.8 to 2.3 pmol of 6 -keto-PGF ${ }_{1 \alpha} / \mathrm{ml}$. This assay has $4 \%$ cross-reactivity with $\mathrm{PGF}_{1 \alpha}, 2 \%$ with $\mathrm{PGF}_{2 \alpha}, 1.6 \%$ with $\mathrm{PGE}_{2}$, and $<1 \%$ with $\mathrm{PGE}_{1}, \mathrm{PGD}$, or $\mathrm{PGD}_{2}$.

Statistical analysis. Statistical significance was determined by the Student's $t$ test; a $P$ value of $<0.005$ was selected to denote statistical significance between groups. Unless indicated otherwise, all data shown are means $\pm S E$ of triplicate determinations from the same experiment. In all cases, similar findings were obtained in a minimum of two other experiments.

\section{RESULTS}

$\mathrm{PGI}_{2}$ synthetase. To determine whether deactivation of $\mathrm{PGI}_{2}$ synthetase occurs in cultured endothelium, we first examined the effect of the PG endoperoxide, $\mathrm{PGH}_{2}$, on $\mathrm{PGI}_{2}$ production by endothelium previously exposed to $\mathrm{PGH}_{2}$. As shown in Fig. 1, prior exposure of the endothelium to $\mathrm{PGH}_{2}$ had no effect on the amount of $\mathrm{PGI}_{2}$ produced in response to a second stimulation by this endoperoxide. In addition, no significant decrease in $\mathrm{PGI}_{2}$ production was observed even after three successive exposures to $\mathrm{PGH}_{2}$ (data not shown). Similar results were obtained when endothelium had been pretreated with $100 \mu \mathrm{M}$ aspirin; thus, the effect of $\mathrm{PGH}_{2}$ is solely attributable to its conversion to $\mathrm{PGI}_{2}$ by $\mathrm{PGI}_{2}$ synthetase, and not to indirect stimulation of earlier steps in the biosynthetic pathway. The finding that the endothelium can re-

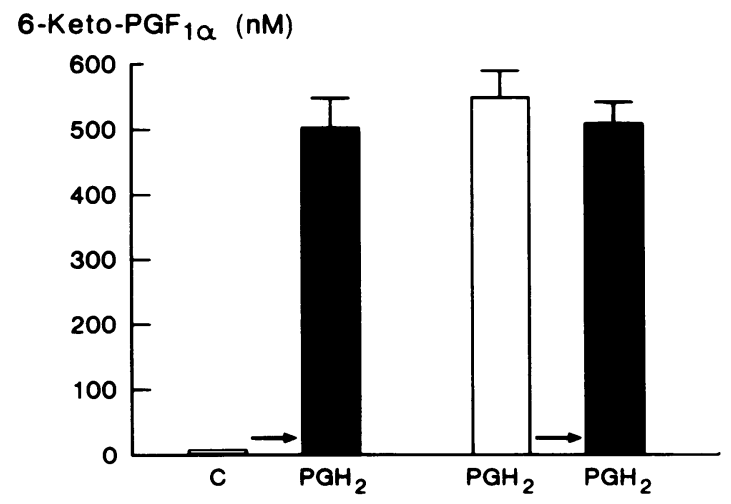

Figure 1 Effect of $\mathrm{PGH}_{2}$ on $\mathrm{PGI}_{2}$ production by endothelium previously exposed to $\mathrm{PGH}_{2}$. Endothelial monolayers were incubated for $10 \mathrm{~min}$ at $37^{\circ} \mathrm{C}$ with either $\mathrm{H} / \mathrm{H}$ buffer alone (control [C]) or buffer containing $\mathrm{PGH}_{2}(4 \mu \mathrm{M}) ; \mathrm{PGI}_{2}$ production during the first incubation is indicated by the open bars. Monolayers were rinsed and then immediately incubated for $10 \mathrm{~min}$ at $37^{\circ} \mathrm{C}$ with $\mathrm{H} / \mathrm{H}$ buffer containing $\mathrm{PGH}_{2}(4 \mu \mathrm{M}) ; \mathrm{PGI}_{2}$ production during the second incubation is indicated by the solid bars. Values given are the means $\pm \mathrm{SE}$ of triplicate determinations from the same experiment; similar findings were obtained in two other experiments. 
spond maximally to multiple stimulations by $\mathrm{PGH}_{2}$ suggests that $\mathrm{PGI}_{2}$ synthetase does not become directly deactivated as a result of the conversion of $\mathrm{PGH}_{2}$ to $\mathrm{PGI}_{2}$. To determine whether events or products generated during earlier steps in the biosynthetic pathway could deactivate $\mathbf{P G I}_{2}$ synthetase, the effect of $\mathbf{P G H}_{2}$ on $\mathrm{PGI}_{2}$ production by endothelium that had first been exposed to other stimuli was studied. Fig. 2 shows that prior stimulation of the endothelium by thrombin, the calcium ionophore A23187 or arachidonic acid had no detectable effect on the capacity of these cells to produce $\mathbf{P G I}_{2}$ in response to subsequent stimulation by $\mathrm{PGH}_{2}$. Together, these findings suggest that deactivation of $\mathbf{P G I}_{2}$ synthetase does not occur in cultured vascular endothelium.

Prostaglandin cyclooxygenase-hydroperoxidase. In sharp contrast to the effect of $\mathrm{PGH}_{2}$, prior exposure of the endothelium to $4 \mu \mathrm{M}$ arachidonic acid markedly decreased $\mathrm{PGI}_{2}$ production in response to an immediate subsequent stimulation by the same concentration of this fatty acid (Fig. 3; right). $\mathrm{PGI}_{2}$ production during a second incubation with arachidonic acid was decreased by an average of $84 \pm 2 \%$ (mean \pm SE of 11 experiments) as compared with the amount released in response to an initial incubation with arachidonic acid. In addition to arachidonic acid, prior exposure of the endothelium to thrombin $(0.5 \mathrm{U} / \mathrm{ml})$ or $\mathrm{A} 23187$ $(4 \mu \mathrm{M})$ significantly decreased $\mathrm{PGI}_{2}$ production in response to subsequent stimulation by arachidonic acid (Fig. 3). On average, the amount of $\mathrm{PGI}_{2}$ produced

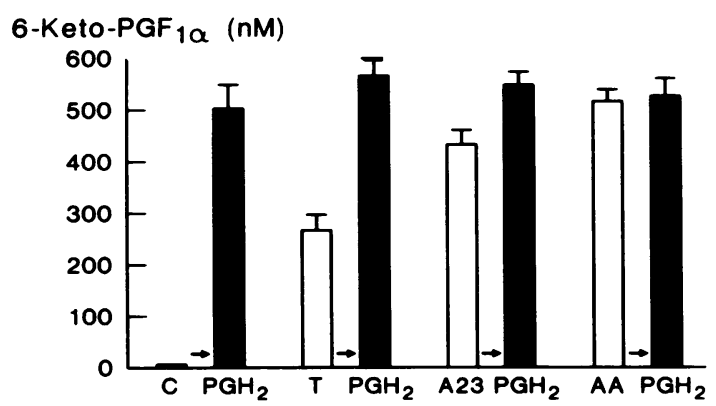

Figure 2 Effect of $\mathrm{PGH}_{2}$ on $\mathrm{PGI}_{2}$ production by endothelium previously exposed to thrombin, A23187, or arachidonic acid. Endothelial monolayers were incubated for $10 \mathrm{~min}$ at $37^{\circ} \mathrm{C}$ with either $\mathrm{H} / \mathrm{H}$ buffer alone (control [C]) or with buffer containing thrombin (T) $(0.5 \mathrm{U} / \mathrm{ml})$, A23187 (A23) $(4 \mu \mathrm{M})$, or arachidonic acid (AA) $(4 \mu \mathrm{M})$. PGI $_{2}$ production during the first incubation is indicated by the open bars. Monolayers were rinsed and then immediately incubated for $10 \mathrm{~min}$ at $37^{\circ} \mathrm{C}$ with $\mathrm{H} / \mathrm{H}$ buffer containing $\mathrm{PGH}_{2}(4 \mu \mathrm{M})$; $\mathrm{PGI}_{2}$ production during the second incubation is indicated by the solid bars. Values given are the means $\pm \mathrm{SE}$ of triplicate determinations from the same experiment; similar findings were obtained in two other experiments.

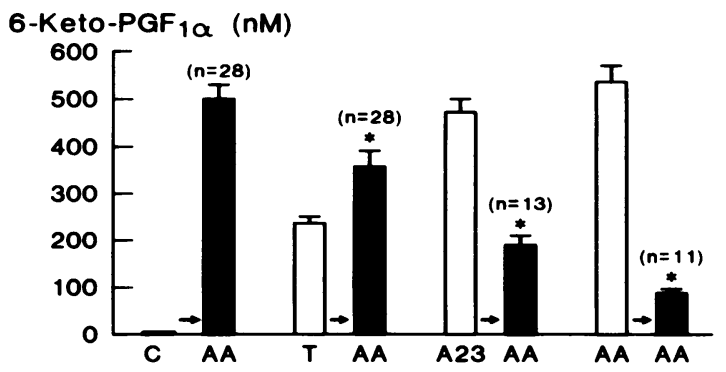

Figure 3 Effect of arachidonic acid on $\mathrm{PGI}_{2}$ production by endothelium previously exposed to thrombin, A23187, or arachidonic acid. Endothelial monolayers were incubated for $10 \mathrm{~min}$ at $37^{\circ} \mathrm{C}$ with $\mathrm{H} / \mathrm{H}$ buffer alone (control [C]) or with buffer containing thrombin (T) $(0.5 \mathrm{U} / \mathrm{ml}), A 23187$ (A23) $(4 \mu \mathrm{M})$, or arachidonic acid (AA) (4 $\mu \mathrm{M})$. PGI Pro- $_{2}$ duction during the first incubation is indicated by the open bars. Monolayers were rinsed and then immediately incubated for $10 \mathrm{~min}$ at $37^{\circ} \mathrm{C}$ with $\mathrm{H} / \mathrm{H}$ buffer containing arachidonic acid $(4 \mu \mathrm{M}) ; \mathrm{PGI}_{2}$ production during the second incubation is indicated by the solid bars. Values given are the means $\pm S E$ of triplicate determinations from the number of experiments indicated in parentheses. The asterisk represents $P<0.005$ comparing $\mathrm{PGI}_{2}$ production by monolayers first incubated with buffer alone.

during a second incubation with arachidonic acid was decreased by $37 \pm 4 \%(n=28$ experiments) and $68 \pm 4 \%$ ( $n=13$ experiments) when the initial stimulus was thrombin or A23187, respectively. Hence the capacity of the endothelium to produce $\mathbf{P G I}_{2}$ in response to subsequent stimulation by arachidonic acid is decreased proportionately to the magnitude of the initial response. As shown in Fig. 4, prior exposure of the endothelium to arachidonic acid decreased $\mathrm{PGI}_{2}$ production in response to subsequent stimulation by either thrombin or A23187. On average, thrombin- or A23187induced release of $\mathrm{PGI}_{2}$ was decreased by $58 \pm 6$ ( $n$ $=11$ experiments) and $61 \pm 2 \%(n=11)$, respectively, as a result of an initial incubation with arachidonic acid. It is important to note that the capacity of arachidonic acid-treated endothelium to respond to thrombin and A23187 was inhibited by the same extent. The concentrations of arachidonic acid, thrombin, and A23187 used in this study are those that stimulated maximal or near-maximal production of $\mathbf{P G I}_{2}$. Lower concentrations of either of these agents during a first incubation had a proportionately smaller effect on the capacity of the endothelium to produce $\mathbf{P G I}_{2}$ in response to subsequent stimulation (data not shown).

Studies with ibuprofen. To test the hypothesis that $\mathrm{PGI}_{2}$ biosynthesis alone causes deactivation of cyclooxygenase, we took advantage of specific properties of ibuprofen, a nonsteroidal antiinflammatory agent (15). In contrast to aspirin, which acetylates cyclooxygenase (16) and thereby produces an irreversible inhibition, the inhibitory effect of ibuprofen is rapidly reversible 


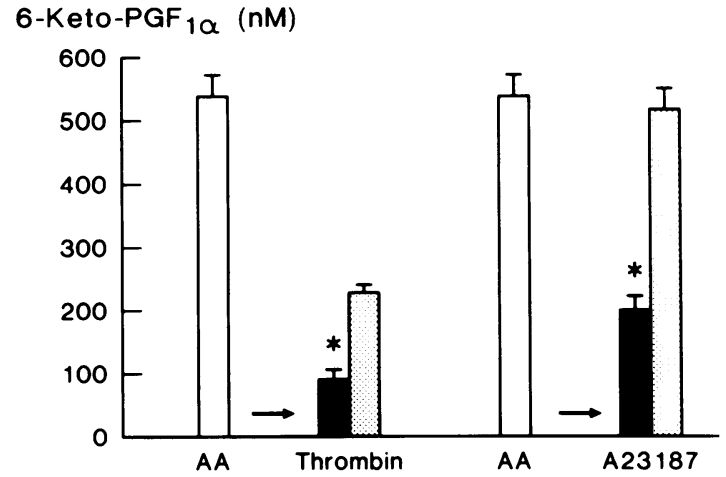

FIGURE 4 Effect of thrombin or A23187 on $\mathrm{PGI}_{2}$ production by endothelium previously exposed to arachidonic acid. Endothelial monolayers were incubated for $10 \mathrm{~min}$ at $37^{\circ} \mathrm{C}$ with $\mathrm{H} / \mathrm{H}$ buffer alone (control; data not shown) or buffer containing arachidonic acid (AA) $(4 \mu \mathrm{M})$. $\mathrm{PGI}_{2}$ production during the first incubation is indicated by the open bars. Monolayers were rinsed and then immediately incubated for $10 \mathrm{~min}$ at $37^{\circ} \mathrm{C}$ with $\mathrm{H} / \mathrm{H}$ buffer containing either thrombin $(0.5 \mathrm{U} / \mathrm{ml})$ or $\mathrm{A} 23187(4 \mu \mathrm{M})$. $\mathrm{PGI}_{2}$ production during the second incubation by monolayers first exposed to arachidonic acid is indicated by the solid bars; the stippled bars indicate $\mathrm{PGI}_{2}$ production by monolayers first exposed to buffer alone. Values given are the means $\pm S E$ of triplicate determinations from nine separate experiments. The asterisk represents $P$ $<0.005$ comparing $\mathrm{PGI}_{2}$ production in response to thrombin or A23187 by monolayers first incubated with arachidonic acid or buffer.

upon removal of the drug (17). Experiments were therefore carried out in which the endothelium was exposed to thrombin, A23187, and arachidonic acid in the presence of ibuprofen; the monolayers were then rinsed and immediately incubated with arachidonic acid. As shown in Fig. 5, preincubation with $250 \mu \mathrm{M}$ ibuprofen blocked $\mathrm{PGI}_{2}$ production in response to thrombin (Fig. 5 A), A23187 (Fig. 5 B), or arachidonic acid (Fig. $5 C$ ). In each case, after removal of ibuprofen and the initial stimulus, $\mathrm{PGI}_{2}$ production in response to subsequent incubation with arachidonic acid was maximal, i.e., the same amount as that produced by monolayers that had first been incubated with either buffer alone or ibuprofen alone. By contrast, monolayers exposed to thrombin, A23187, or arachidonic acid in the absence of ibuprofen exhibited a typical, marked reduction in $\mathrm{PGI}_{2}$ release in response to subsequent stimulation by arachidonic acid (Fig. 5 $A-C)$. Similar findings to those summarized in Fig. 5 were obtained when monolayers were first exposed to arachidonic acid in the presence of ibuprofen followed by a second stimulation with either thrombin or A23187 (data not shown). By inhibiting cyclooxygenase activity with ibuprofen, this enzyme is thus protected from deactivation during exposure to any given
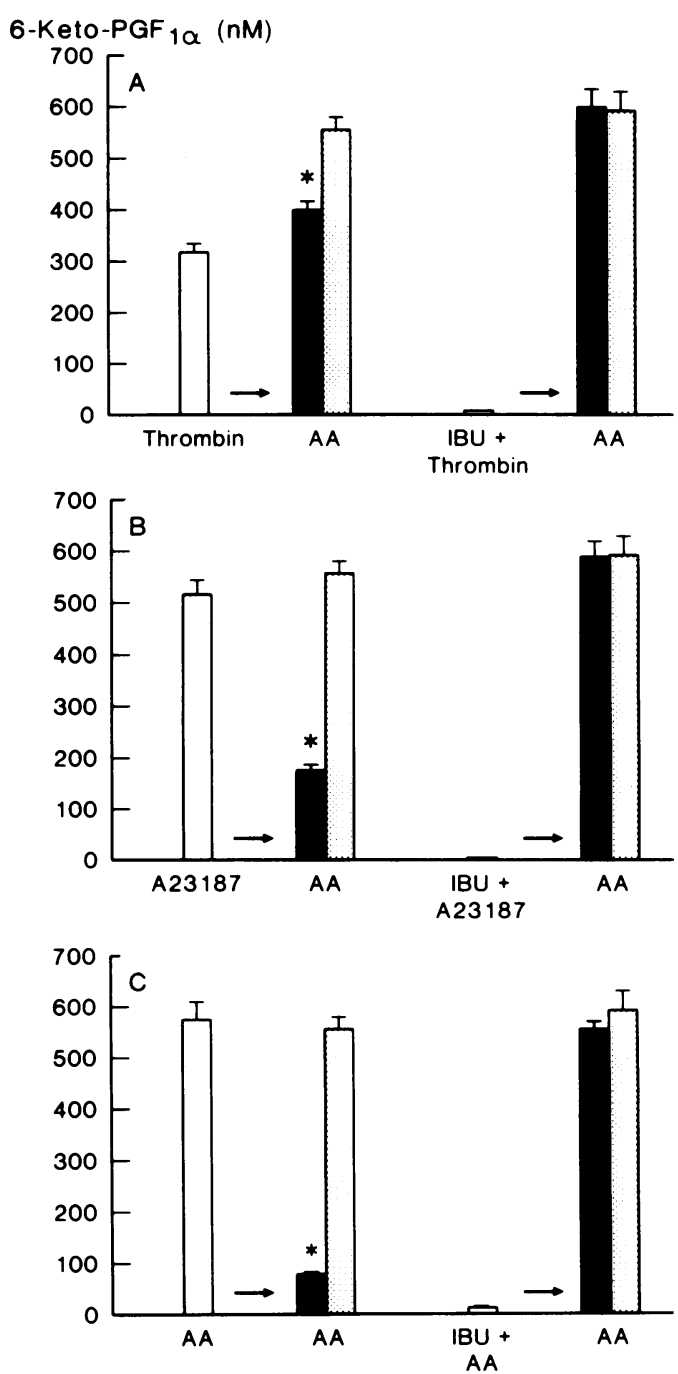

FIGURE 5 Effect of arachidonic acid on $\mathrm{PGI}_{2}$ production by endothelium previously exposed to thrombin, A23187, or arachidonic acid in the presence of ibuprofen. Endothelial monolayers were preincubated for $5 \mathrm{~min}$ at $37^{\circ} \mathrm{C}$ with $\mathrm{H} /$ $\mathrm{H}$ buffer alone or buffer containing ibuprofen (IBU) (250 $\mu \mathrm{M})$. After preincubation, thrombin $(0.5 \mathrm{U} / \mathrm{ml})(A), \mathrm{A} 23187$ $(4 \mu \mathrm{M})(B)$, or arachidonic acid (AA) $(4 \mu \mathrm{M})(C)$ was added to the monolayers, which were then incubated for $10 \mathrm{~min}$ at $37^{\circ} \mathrm{C} ; \mathrm{PGI}_{2}$ production during the preincubation and incubation periods is indicated by the open bars. Monolayers were rinsed and then immediately incubated for $10 \mathrm{~min}$ at $37^{\circ} \mathrm{C}$ with arachidonic acid $(4 \mu \mathrm{M})$. $\mathrm{PGI}_{2}$ production during the second incubation by monolayers first exposed to thrombin, A23187, or arachidonic acid in the presence or absence of ibuprofen is indicated by the solid bars; the stippled bars indicate $\mathrm{PGI}_{2}$ production in response to arachidonic acid by monolayers incubated with buffer alone. Values given are the means $\pm S E$ of triplicate determinations from the same experiment; similar findings were obtained in four other experiments. The asterisk represents $P<0.005$ comparing $\mathrm{PGI}_{2}$ production in response to arachidonic acid by monolayers first incubated with thrombin or buffer $(A)$, with A23187 or buffer $(B)$, or with arachidonic acid or buffer $(C)$. 
stimulus of $\mathrm{PGI}_{2}$ biosynthesis; however, as ibuprofen acts only on cyclooxygenase, earlier steps in the biosynthetic pathway are unaltered. The results summarized in Fig. 5 suggest that the metabolism of arachidonic acid alone causes a direct deactivation of cyclooxygenase and that events or products of earlier steps in the pathway of $\mathrm{PGI}_{2}$ biosynthesis have no direct or indirect inhibitory effect on the capacity of the endothelium to produce $\mathrm{PGI}_{2}$ in response to arachidonic acid.

Effect of antioxidants. Several studies have shown that a variety of antioxidants are effective in protecting microsomal and purified forms of cyclooxygenase from deactivation $(7,8,18,19)$. We have tested the effects of several antioxidants on arachidonic acid-induced stimulation of $\mathbf{P G I}_{2}$ biosynthesis with the aim of determining whether these agents can affect cyclooxygenase activity in intact cells. Neither ascorbic acid $(2 \mathrm{mM})$ nor reduced glutathione $(10 \mathrm{mM})$ had a significant effect on $\mathrm{PGI}_{2}$ production; however, $\boldsymbol{n}$-propyl gallate $(200 \mu \mathrm{M})$, methyl-phenyl-sulfide $(1 \mathrm{mM})$, and dithiothreitol $(10 \mathrm{mM})$ inhibited $\mathrm{PGI}_{2}$ production by 80,43 , and $97 \%$, respectively. Preliminary studies demonstrated a dose-dependent relationship of the inhibitory effects of these agents. Each agent produced a similar inhibitory effect regardless of whether it was added before or simultaneously with arachidonic acid. The effect of methyl-phenyl-sulfide was reversible upon rinsing the endothelium; the reversibility of $n$ propyl gallate and dithiothreitol was not determined. All of the agents studied had similar effects on $\mathbf{P G I}_{2}$ production in response to thrombin or A23187.
Recovery of responsiveness to arachidonic acid. In light of the possibility that deactivation of cyclooxygenase may play an important role in limiting $\mathbf{P G I}_{2}$ production by vascular endothelium, studies were carried out to determine the duration of this phenomenon. Since deactivation of cyclooxygenase and inhibition of its activity by aspirin result in the same net effect on $\mathrm{PGI}_{2}$ production, the capacity of the endothelium to recover from both was compared in order to provide some perspective. The protocol used in these experiments was as follows: monolayers were first incubated for $30 \mathrm{~min}$ at $37^{\circ} \mathrm{C}$ with $\mathrm{H} / \mathrm{H}$ buffer alone or buffer containing $4 \mu \mathrm{M}$ arachidonic acid or $100 \mu \mathrm{M}$ aspirin; monolayers were then rinsed with buffer, and allowed to 'recover' for 1,24 , or $48 \mathrm{~h}$ in culture medium containing $20 \%$ fetal calf serum; recovery incubations were carried out in a $95 \%$ air $/ 5 \% \mathrm{CO}_{2}$ atmosphere. After the recovery period, monolayers were again rinsed and incubated for $30 \mathrm{~min}$ at $37^{\circ} \mathrm{C}$ with $4 \mu \mathrm{M}$ arachidonic acid. As shown in Table $\mathrm{I}, \mathrm{PGI}_{2}$ production in response to a second stimulation by arachidonic acid was restored to $70 \%$ of maximal after a $48-\mathrm{h}$ recovery period. Significantly less recovery to stimulation by arachidonic acid was observed in monolayers first incubated with aspirin. In three experiments, recovery of arachidonic acid-treated monolayers averaged $34 \pm 4$, $69 \pm 4$, and $74 \pm 2 \%$, whereas recovery of aspirin-treated monolayers was $18 \pm 1,36 \pm 2$, and $37 \pm 2 \%$ after 1,24 , and $48 \mathrm{~h}$, respectively (means $\pm \mathrm{SE}$ ). Similar results were obtained when monolayers were allowed to recover in serum-free culture medium. Reduction of the aspirin concentration from 100 to $40 \mu \mathrm{M}$ resulted in

TABLE I

Recovery of Responsiveness to Arachidonic Acid After an Initial Exposure of Endothelial Monolayers to Arachidonic Acid or Aspirin

\begin{tabular}{|c|c|c|c|}
\hline \multirow{2}{*}{$\frac{\text { First incubation }}{\mathrm{O} \mathrm{h}^{\circ}}$} & \multicolumn{3}{|c|}{ Second incubation (Arachidonic acid, $4 \mu \mathrm{M}$ ) } \\
\hline & $1 \mathrm{~h}$ & $24 \mathrm{~h}$ & $48 \mathrm{~h}$ \\
\hline Control & $448 \pm 22(100 \%)$ & $419 \pm 13(100 \%)$ & $490 \pm 62(100 \%)$ \\
\hline Arachidonic acid & $139 \pm 17(31 \%)$ & $260 \pm 8 \quad(62 \%)$ & $343 \pm 4 \quad(70 \%)$ \\
\hline Aspirin & $67 \pm 3 \quad(15 \%)$ & $173 \pm 5 \quad(41 \%)$ & $189 \pm 7 \quad(39 \%)$ \\
\hline
\end{tabular}

- Endothelial monolayers were first incubated for $30 \mathrm{~min}$ at $37^{\circ} \mathrm{C}$ with $\mathrm{H} / \mathrm{H}$ buffer alone (control) or buffer containing arachidonic acid $(4 \mu \mathrm{M})$ or aspirin $(100 \mu \mathrm{M})$. During

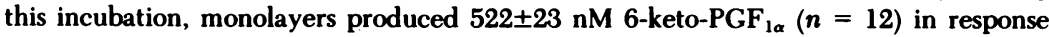
to arachidonic acid. Incubation with aspirin inhibited $\mathbf{P G I}_{2}$ production in response to an immediate subsequent incubation with arachidonic acid by $100 \%$. After the first incubation, monolayers were rinsed and allowed to 'recover' for 1,24 , and $48 \mathrm{~h}$ in culture medium containing $20 \%$ fetal calf serum. Values given reflect 6 -keto-PGF ${ }_{1 \alpha}$ production in response to a subsequent incubation $\left(30 \mathrm{~min}\right.$ at $\left.37^{\circ} \mathrm{C}\right)$ with arachidonic acid $(4 \mu \mathrm{M})$. Base-line production of 6 -keto- PGF $_{1 \alpha}$ has been substracted; the numbers in parentheses reflect the recovery of the endothelium to stimulation by arachidonic acid. Values given are the means $\pm \mathrm{SE}$ of triplicate determinations from the same experiment; similar findings were obtained in two other experiments. 
recoveries comparable to those observed with arachidonic acid-treated monolayers (data not shown). These findings suggest that the effect of deactivation, like those of aspirin, are long lasting, are likely to be irreversible and, thus, to require de novo synthesis of the enzyme.

\section{DISCUSSION}

The data presented in this paper demonstrate that $\mathbf{P G I}_{2}$ biosynthesis in cultured vascular endothelium results in deactivation of cyclooxygenase-hydroperoxidase but has no effect on the activity of $\mathbf{P G I}_{2}$ synthetase. This conclusion is based on the following lines of evidence. The finding that both untreated and aspirintreated endothelium respond maximally to multiple simulations by $\mathrm{PGH}_{2}$ suggests that $\mathrm{PGI}_{2}$ synthetase does not become deactivated as a result of the conversion of $\mathrm{PGH}_{2}$ to $\mathrm{PGI}_{2}$. Furthermore, the lack of a detectable effect of thrombin, A23187, or arachidonic acid on the capacity of the endothelium to produce $\mathrm{PGI}_{2}$ in response to subsequent stimulation by $\mathrm{PGH}_{2}$ shows that events or products generated during earlier steps in the biosynthetic pathway do not affect the activity of $\mathbf{P G I}_{2}$ synthetase. In light of these results, the observation that prior exposure of the endothelium to arachidonic acid markedly decreased the amount of $\mathbf{P G I}_{2}$ produced in response to subsequent stimulation by this fatty acid suggests that cyclooxygenase itself becomes deactivated as a result of the metabolism of arachidonic acid. Additional evidence in support of this conclusion is provided by the finding that other stimuli of $\mathbf{P G I}_{2}$ biosynthesis, such as thrombin and A23187, likewise decreased the responsiveness of the endothelium to arachidonic acid, and that prior exposure of the endothelium to arachidonic acid decreased the amount of $\mathrm{PGI}_{2}$ produced in response to subsequent stimulation by thrombin or A23187. In general, the capacity of the endothelium to produce $\mathrm{PGI}_{2}$ in response to subsequent stimulation was decreased proportionately to the magnitude of the initial response. To demonstrate conclusively that the actual metabolism of arachidonic acid by cyclooxygenasehydroperoxidase causes deactivation of this enzyme, studies with ibuprofen were carried out. The finding that ibuprofen effectively protected cyclooxygenase from deactivation during exposure to any given stimulus of $\mathrm{PGI}_{2}$ biosynthesis shows that the metabolism of arachidonic acid alone, and not events or products of earlier steps in the pathway causes deactivation of this enzyme.

Extensive studies of microsomal and purified preparations of prostaglandin cyclooxygenase-hydroperoxidase have shown that both the oxygenase $(2,21)$ and peroxidase $(7,8)$ activities become irreversibly deac- tivated during catalysis. Since autoinactivation occurs with several hydroperoxides in the absence of oxygenase reaction, Egan et al. $(7,8)$ have ascribed this phenomenon to attack on the enzyme by a species generated by the hydroperoxidase reaction. The ability of this oxidant to deactivate other enzymes, such as the hydroperoxidase itself $(21)$ and $\mathrm{PGI}_{2}$ synthetase (9), has also been established. Egan et al. (7, 8, 20, 21) have shown that deactivation of cyclooxygenase-hydroperoxidase is attenuated by a variety of reducing antioxidants. At micromolar concentrations, phenol (7) and organic sulfides, such as methyl-phenyl-sulfide $(18,20)$, increase the extent and rate of both oxygenation of arachidonic acid by prostaglandin cyclooxygenase and reduction of hydroperoxides by the accompanying hydroperoxidase; higher concentrations are inhibitory. Likewise, both ascorbic acid and $n$-propyl gallate were found to enhance the formation of 6-keto$\mathrm{PGF}_{1 \alpha}$, apparently by shifting the metabolism of $\mathrm{PGH}_{2}$ from nonenzymic decomposition to enzymic formation of $\mathrm{PGI}_{2}(19)$. In this case, the antioxidants were thought to act by protecting $\mathrm{PGI}_{2}$ synthetase from deactivation. Although the results of the present study demonstrate that deactivation of cyclooxygenase-hydroperoxidase occurs in cultured endothelium, it is not known whether deactivation of this enzyme in intact cells involves the same mechanism as that described for microsomal and purified preparations. In contrast to the effect of antioxidants in subcellular preparations, methyl-phenyl-sulfide, $n$-propyl gallate, and dithiothreitol markedly inhibit PGI $_{2}$ production in a dosedependent relationship in endothelium, whereas neither ascorbic acid nor reduced glutathione has a significant effect. These findings may be interpreted to suggest that deactivation of cyclooxygenase in intact cells, such as cultured endothelium, does not involve attack on this enzyme by a peroxidase-dependent oxidant. Alternatively, inhibition of cyclooxygenase activity by antioxidants may result from a reduction in the level of endogenous hydroperoxide below that needed to initiate optimal catalysis $(8,21)$.

Deactivation of cyclooxygenase markedly decreased the capacity of the endothelium to produce $\mathrm{PGI}_{2}$ for prolonged periods of time. The duration and magnitude of the effect of deactivation on the responsiveness of the endothelium to stimuli of $\mathrm{PGI}_{2}$ biosynthesis are comparable to the effects of aspirin. In this regard, the effects of deactivation appear to be irreversible; recovery of the capacity of the endothelium to produce $\mathrm{PGI}_{2}$ is likely to require de novo biosynthesis of the enzyme.

In conclusion, we suggest that the regulation of $\mathrm{PGI}_{2}$ production in normal vascular endothelium may partly be a function of the activity and biosynthesis of cyclooxygenase-hydroperoxidase and that deactivation 
of this enzyme may be a primary factor limiting the capacity of the endothelium to produce $\mathrm{PGI}_{2}$. Studies are presently underway to characterize this phenomenon further in cultured endothelium and to determine whether deactivation occurs in vivo. Understanding of the mechanism of deactivation may permit the development of specific protective drugs.

\section{ACKNOWLEDGMENTS}

We thank Candace Funk for excellent technical assistance, Glenna Fry and Connie Schroeder for preparation of the cell cultures, and Barbara Freiburg for typing the manuscript.

This work was supported, in part, by grants HL-14320 (Specialized Center of Research in Atherosclerosis), HL22408-03 and HL-27561 from the National Heart, Lung, and Blood Institute, and grant 81-852 from the American Heart Association.

\section{REFERENCES}

1. Moncada, S., E. A. Higgs, and J. R. Vane. 1977. Human arterial and venous tissues generate prostacyclin (prostaglandin $\mathrm{X}$ ), a potent inhibitor of platelet aggregation. Lancet. I:18-21.

2. Gorman, R. R., S. Bunting, and O. V. Miller. 1977. Modulation of human platelet adenylate cyclase by prostacyclin (PGX). Prostaglandins. 13:377-388.

3. Weksler, B. B., C. W. Ley, and E. A. Jaffe. 1978. Stimulation of endothelial cell prostacyclin production by thrombin, trypsin, and ionophore A23187. J. Clin. Invest. 62:923-930.

4. Brotherton, A. F. A., and J. C. Hoak. 1982. Role of $\mathrm{Ca}^{2+}$ and cyclic AMP in the regulation of the production of prostacyclin by the vascular endothelium. Proc. Natl. Acad. Sci. USA. 74:495-499.

5. Czervionke, R. L., J. B. Smith, J. C. Hoak, G. L. Fry, and D. L. Haycraft. 1979. Use of a radioimmunoassay to study thrombin-induced release of $\mathrm{PGI}_{2}$ from cultured endothelium. Thromb. Res. 14:781-786.

6. Brotherton, A. F. A., D. E. Macfarlane, and J. C. Hoak. 1982. Prostacyclin biosynthesis in vascular endothelium is not inhibited by cyclic AMP. Studies with 3-isobutyl1-methylxanthine and forskolin. Thromb. Res. 28:637647.

7. Egan, R. W., J. Paxton, and F. A. Kuehl, Jr. 1976. Mechanism for irreversible self-deactivation of prostaglandin synthetase. J. Biol. Chem. 251:7329-7335.

8. Egan, R. W., P. H. Gale, E. M. Baptista, K. L. Kennicott, W. J. A. VandenHeuvel, R. W. Walker, P. E. Fagerness, and F. A. Kuehl, Jr. 1981. Oxidation reactions by pros- taglandin cyclooxygenase-hydroperoxidase. J. Biol. Chem. 256:7352-7361.

9. Ham, E. A., R. W. Egan, D. D. Soderman, P. H. Gale, and F. A. Kuehl, Jr. 1979. Peroxidase-dependent deactivation of prostacyclin synthetase. J. Biol. Chem. 254:2191-2194.

10. Brotherton, A. F. A., and J. C. Hoak. 1982. Deactivation of cyclooxygenase in vascular endothelium during $\mathrm{PGI}_{2}$ biosynthesis. Circulation. 66:II-178.

11. Gorman, R. R., F. F. Sun, O. V. Miller, and R. V. Johnson. 1977. Prostaglandins $H_{1}$ and $H_{2}$. Convenient biochemical synthesis and isolation. Further biological and spectroscopic characterization. Prostaglandins. 13:10431053.

12. Smith, J. B., M. L. Ogletree, A. J. Lefer, and K. C. Nicolaou. 1978. Antibodies which antagonize the effects of prostacyclin. Nature (Lond.). 274:64-65.

13. Czervionke, R. L., J. C. Hoak, and G. L. Fry. 1978. Effect of aspirin on thrombin-induced adherence of platelets to cultured cells from the blood vessel wall. $J$. Clin. Invest. 62:847-856.

14. Jaffe, E. A., R. L. Nachman, C. G. Becker, and C. R. Minick. 1973. Culture of human endothelial cells derived from umbilical veins. Identification of morphologic and immunologic criteria. J. Clin. Invest. 52:27452756.

15. McIntyre, B. A., and R. B. Philip. 1977. Effect of three non-steroidal anti-inflammatory agents on platelet function and prostaglandin synthesis in vitro. Thromb. Res. 12:67-77.

16. Roth, G. J., N. Stanford, and P. W. Majerus. 1975. Acetylation of prostaglandin synthase by aspirin. Proc. Natl. Acad. Sci. USA. 72:3073-3076.

17. Parks, W. M., J. C. Hoak, and R. L. Czervionke. 1981. Comparative effect of ibuprofen on endothelial and platelet prostaglandin synthesis. J. Pharmacol. Exp. Ther. 219:415-419.

18. Smith, W. L., and W. E. M. Lands. 1971. Stimulation and blockade of prostaglandin biosynthesis. J. Biol. Chem. 246:6700-6702.

19. Beetens, J. R., M. Claeys, and A. G. Herman. 1981. Antioxidants increase the formation of 6-oxo-PGF PG $_{1 \alpha}$ by $\mathrm{ram}$ seminal vesicle microsomes. Biochem. Pharmacol. 30:2811-2815.

20. Egan, R. W., P. H. Gale, and F. A. Kuehl, Jr. 1979. Reduction of hydroperoxides in the prostaglandin biosynthetic pathway by a microsomal peroxidase. J. Biol. Chem. 254:3295-3302.

21. Egan, R. W., P. H. Gale, G. C. Beveridge, L. J. Marrett, and F. A. Kuehl, Jr. 1980. Direct and indirect involvement of radical scavengers during prostaglandin biosynthesis. Adv. Prostaglandin Thromboxane Res. 6:153155. 